
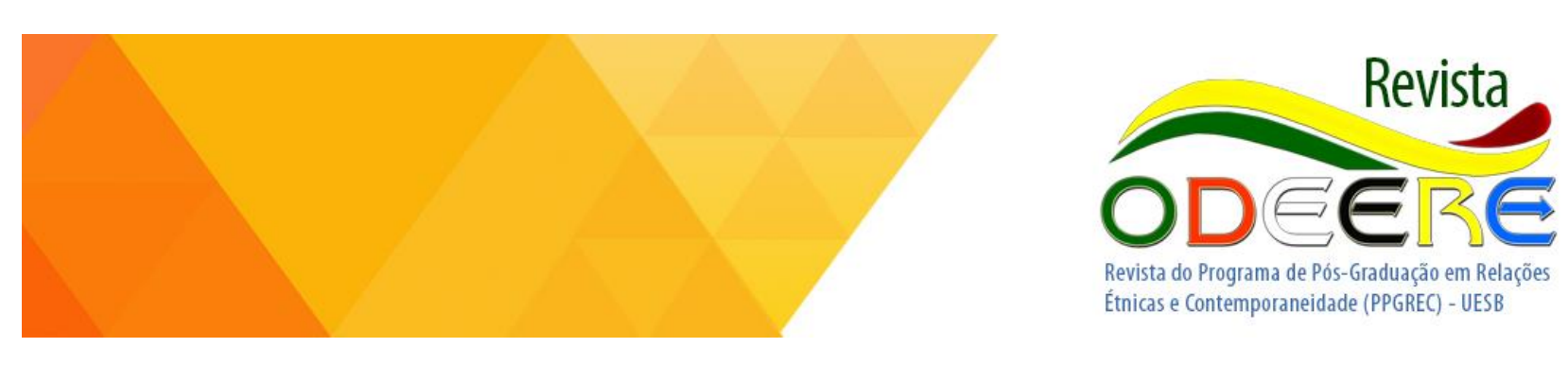

\title{
Quilombo: para além da
}

Resenha: LEITE, Maria Jorge dos Santos. Movimento Social Quilombola: processos educativos. 1ed. Curitiba: Appris, 2016, 271 p.

\section{territorialidade}

\author{
Vivian Ingridy de Carvalho Lima \\ Universidade Estadual do Sudoeste da \\ Bahia (UESB) \\ vivianpsicoufba@gmail.com
}

Os processos educativos dentro do movimento social quilombola ainda se constituem um tema pouco explorado pela bibliografia em diferentes áreas, por isso a relevância dessa obra para ampliar as discussões, tomando a concepção de quilombola como sujeito de direitos civis, políticos e sociais e ainda enquanto sujeitos coletivos: relativos a gênero, geração, identidade e minorias étnicas, culturais e ambientais.

Maria Jorge dos Santos Leite, nasceu na cidade de Jardim, CE, em 10 de setembro de 1960, Graduada em História pela Universidade Regional do Cariri (URCA), mestre em Sociologia peal Universidade Federal do Ceará (UFC) e doutora em Educação pela mesma Universidade; professora aposentada da Rede Pública Estadual de Pernambuco. É coautora do livro Educação quilombola: Um estudo de caso na comunidade de Conceição das Crioulas, Pernambuco (2011) e diversos artigos publicados em revistas, periódicos e anais de eventos.

A obra é resultado de uma pesquisa realizada na comunidade quilombola de Conceição das Crioulas no município de Salgueiro, sertão central de Pernambuco nos anos de 1999 e 2001 e em 2009 e 2012. A questão fundiária relatada no texto é pano de fundo para as tensões que os quilombolas de Conceição vêm enfrentando desde a sua constituição. Aborda também, a origem 
do movimento social quilombola, bem como a constituição desse movimento como político, uma vez que o reconhecimento da comunidade como quilombola implica a constituição dos sujeitos de direito agindo na coletividade, daí a relevância da obra em destacar ao longo de sua escrita o termo sujeito coletivo enquanto sujeitos de sua própria ação política e emancipatória.

Nesta perspectiva sociológica e marxista Maria Jorge apresenta de forma sistematizada o processo histórico político de luta do movimento negro no Brasil a partir da década de 70, como o reconhecimento de direitos às populações negras, de forma dialética para que os leitores compreendam a relação desse movimento e sua contribuição para a constituição do movimento negro e quilombola na luta por direitos étnicos na Comunidade de Conceição das Crioulas.

Outro ponto relevante da obra é que a autora consegue tratar de diversas questões de forma interligada, questões estas que podem contribuir para as pesquisas sobre quilombos e movimentos sociais, a exemplo, a identidade étnica, gênero, associações, questão fundiária, territorialidade, entre outros. Contribui também para avançar o debate sobre quilombolas como sujeitos de identidades diversas que lutam por diversas causas, além daquelas historicamente reconhecidas.

O livro é dividido em 3 capítulos, onde a autora descreve o percurso de sua pesquisa etnográfica realizada na comunidade quilombola Conceição das Crioulas. No primeiro capítulo Estrutura Fundiária e Resistência na Terra das Crioulas, a autora faz uma reconstituição das origens da comunidade, a partir dos relatos orais dos moradores da comunidade, dos registros dos laudos antropológicos, dissertações e do jornal da própria comunidade. Conceição das Crioulas tem sua origem nos primeiros anos do século XIX, quando seis negras, escravas fugitivas, arrendaram 3 léguas em Salgueiro, sertão central de Pernambuco, que pagavam com a produção e fiação de algodão que vendiam na cidade de Flores, sertão do Pajeú, adquirindo posteriormente o título de suas terras. Nesse processo de escrita, a autora retrata os desafios que a comunidade enfrenta desde as suas origens, que é a luta pelo direito ao acesso e o uso do território, causas que vão além de interesses econômicos, mas o pertencimento geracional, afetivo, étnico, cultural e territorial, ao trabalho coletivo, marcas de resistência de um povo e da expropriação da terra, sendo uma realidade atual no Brasil.

Tendo em vista a questão do uso da terra no Brasil, a historiadora faz um resgate histórico das leis que regulamentaram o uso e a posse da terra desde o sistema de Capitanias Hereditárias, com as doações de sesmarias; as leis do século XIX que proibiam a aquisição de terras devolutas

Odeere: revista do programa de pós-graduação em Relações Étnicas e Contemporaneidade - UESB. Ano 1, número 1, volume 1, Janeiro - Junho de 2016. 
apenas por meio da compra, como a Constituição Republicana de 1891, que transferiu as terras para o Estado, beneficiando as elites fazendeiros e, no século XX, com a Constituição de 1945, que não avançou em nada a questão latifundiária no Brasil.

Além da contextualização sobre o uso e a posse da terra, o livro - Movimento Social Quilombola traz para o debate a problematização dos movimentos sociais que defendem a questão da terra como a Liga Camponesa e a participação política do Movimento Negro, trazendo à tona a questão dos direitos territoriais das comunidades quilombolas, culminando posteriormente, no Artigo 68 do ato das Disposições Constitucionais Transitórias (ADCT), reconhecendo às comunidades quilombolas a propriedade definitiva da posse da terra.

A pesquisadora retoma no capítulo a discussão principal da obra sobre o processo histórico de luta pela posse da terra na Comunidade de Conceição das Crioulas enfatizando as disputas e tensões entre fazendeiros e quilombolas, apesar do reconhecimento pelo Estado concedendo a posse de 17 mil hectares à comunidade (30\% da área original). Embora, mesmo depois do título para parte dos moradores, a comunidade enfrenta grandes desafios em suas relações de trabalho, já que nem todos tem o título da terra, inviabilizando o crédito rural e a para garantir a autonomia desses sujeitos. Assim, a posse e luta pela terra é uma questão de identidade étnica e cultural, uma luta por direitos, por cidadania, pela coletividade pelas gerações futuras.

Já o segundo capítulo - Movimentos Sociais: a constituição do sujeito coletivo, propõe uma discussão sobre a categoria movimentos sociais, tendo como fundamento a constituição do sujeito coletivo como aquele que toma consciência das causas e consequências dos problemas políticos e sociais de sua comunidade, agindo no sentido de provocar mudanças. Nesse processo de mudança, o livro enfatiza os principais elementos para a construção da identidade desses sujeitos, principalmente a identidade étnica, avança também o debate para as relações de gênero, a exemplo o protagonismo feminino para a comunidade e ainda, as relações étnicas existentes em seu território.

Nessa proposta, a obra destaca esses sujeitos como histórico, político, social e coletivo. Para tanto, historiciza de forma suscita a força que o Movimento Negro retoma em 1970 e sua relevância política para o surgimento do movimento nacional das comunidades rurais quilombolas, e neste caso, para a constituição do sujeito coletivo da comunidade a partir da mobilização da comunidade em 1987, resultando no movimento negro quilombola de Conceição das Crioulas, que culminou na articulação com o Movimento Negro Unificado (MNU), com grupos 
negros, com o Partido dos Trabalhadores (PT), Pastoral da Terra, Sindicatos de Trabalhadores Rurais, ONGs e assim, ganhando força para a luta pelos seus direitos étnicos e territoriais. $\mathrm{O}$ movimento social da comunidade ganhou legitimidade quando em 1998 quando a comunidade foi reconhecida enquanto quilombola pela Fundação Cultural Palmares e a titulação da terra em 2000.

Na constituição dessa identidade coletiva, a autora retrata através dos relatos, os embates e as barreiras impostas pelas instituições locais á comunidade e ainda, a falta de reconhecimento étnico por parte dos seus membros, destacando o embate jurídico e a negociação da desapropriação das terras. As relações étnicas se acentuam de sobremaneira, com a disputa política entre os partidos que apoiam de um lado os quilombolas e de outro os indígenas.

Nesse mesmo embate há uma disputa no campo religioso em relação ao mito fundador da comunidade que os quilombolas defendem ser da origem do mito das 6 crioulas e o outro grupo, conforme exposto na obra, "os brancos", referem-se aos fazendeiros, que defendem o mito de que nossa Senhora da Assunção intercedeu à uma promessa da esposa de um fazendeiro, acontecendo a realização de duas festas durante o ano. No entanto, há um sincretismo religioso da comunidade baseado em crenças católicas, evangélicas, indígenas e africanas.

É importante destacar que o termo relações étnicas não é utilizado neste texto, em nenhum momento foi utilizado pela autora, sendo preferido o termo relações étnico-raciais. Outro elemento constitutivo da identidade étnica apresentado pela pesquisa é o protagonismo feminino que teve influência histórica desde suas origens na luta pela posse e recuperação das terras. Todo esse percurso que a autora utilizou foi para a compreensão de como o movimento político e social se constituiu na comunidade, resultando na Associação Quilombola de Conceição das Crioulas (AQC), fundada em 2000, sem fins lucrativos, composta por 10 associações de produtores e trabalhadores rurais provenientes dos diversos sítios e vilas que compõem a comunidade, tem como principal luta além da regularização fundiária está uma educação específica e diferenciada que a autora irá trazer com maior aprofundamento no capítulo posterior. Além da associação, a comunidade tem o Jornal Crioulas, que se constitui um recurso importante para a formação e divulgação de assuntos relevantes relacionados à comunidade.

No último capítulo - Direitos Quilombolas: os caminhos do reconhecimento, a autora enfatiza o debate para o campo dos direitos quilombolas, trazendo 2 conceitos relevantes: ações afirmativas e direitos étnicos, que segundo a obra, são políticas "compensatórias" com o objetivo 
de "reparar" os danos sofridos pelos negros afro-brasileiros, por meio da escravidão, e por seus descendentes socialmente excluídos do acesso aos bens materiais e culturais da sociedade brasileira depois da abolição (p. 194).

Dentre as políticas de ações afirmativas levantadas pela obra, estão o Estatuto da Igualdade Racial e o sistema de cotas. No entanto, não discorreu sobre essas políticas, trazendo uma discussão restrita a narrativa de duas integrantes da comunidade em que uma apoia as ações afirmativas e a outra é contrária. Por outro lado, um ponto bastante relevante trazida pela obra para ampliar a reflexão sobre os direitos quilombolas, está a questão da educação diferenciada, que encontra respaldo na Constituição Federal de 1988, na Lei de Diretrizes e Bases da Educação Nacional 9394/96 (LDBN) e na implementação da Lei 10.639/03. A educação diferenciada, uma das bandeiras de luta da comunidade, fundamenta-se na valorização dos saberes, na história, na memória e cultura como constituintes de suas identidades, tendo como espaço escolar as discussões do próprio movimento quilombola.

A autora aponta ainda, alguns avanços e os limites da implementação da Lei 10.639/03 e como isso se reflete nas dificuldades enfrentadas pela comunidade, a exemplo, da formação de professores e a precariedade do material didático pedagógico sobre a temática. Ao longo desse capítulo fica evidente através de excertos das narrativas dos moradores, situações de exclusão e humilhação vivenciadas por esses sujeitos ou da história oral de seus ancestrais. Ao final, a questão do direito à terra e conflitos territoriais são retomados a partir da Constituição Federal e do artigo 68 do ADCT e das questões relacionadas ao enfrentamento histórico entre fazendeiros e quilombola, questões estas já debatidas nos capítulos anteriores.

A obra é relevante porque além de fazer uma contextualização sobre o processo histórico da origem da comunidade e da constituição da identidade étnica e coletiva, nos permite também, refletir sobre categorias de análise como identidade étnica e relações étnicas, tendo como base autores com Stuart Hall, Frederick Bart e as Leis voltadas para garantir o reconhecimento por parte do Estado de que a população brasileira é composta por diferentes grupos sociais e que uns são grupos excluídos e marginalizados socialmente. 
Vivian Ingridy de Carvalho Lima: Possui graduação em Pedagogia pela Universidade Estadual do Sudoeste da Bahia (UESB), especialização em Educação e Diversidade Étnico-Cultural - UESB, graduanda em Psicologia pela Universidade Federal da Bahia (UFBA) e mestranda do Programa de Pós-Graduação em Relações Étnicas e Contemporaneidade - UESB. Atualmente atua no atendimento psicopedagógico pela Prefeitura Municipal de Planalto - BA. Experiência na área de Educação atuando como coordenadora pedagógica do Ensino Fundamental e EJA, professora dos anos iniciais e finais do Ensino Fundamental e educação do campo, formação de professores pelo Programa Pacto Nacional Pela Alfabetização na Idade Certa (PNAIC). Atuou como monitora voluntária do projeto de pesquisa (UFBA) intitulado "Desenvolvimento de um programa de intervenção cognitiva para idosos".

Artigo recebido para publicação em: Maio de 2016.

Artigo aprovado para publicação em: Junho de 2016. 